\title{
The Contingency of Leibniz's PRINCIPLE OF THE IDENTITy OF INDISCERNIBLES
}

\author{
JULIA JORATI \\ The Ohio State University
}

\begin{abstract}
Leibniz's famous Principle of the Identity of Indiscernibles (PII) states that no two things are exactly alike. The PII is commonly thought to be metaphysically necessary for Leibniz: the coexistence of two indiscernibles is metaphysically impossible. This paper argues, against the standard interpretation, that Leibniz's PII is metaphysically contingent. In other words, while the coexistence of indiscernibles would not imply a contradiction, the PII is true in the actual world because the Principle of Sufficient Reason rules out violations of the PII. God could have created indiscernibles but he did not because he is wise and does nothing without a sufficient reason. Because it is plausible that all Leibnizian possible worlds are unified by a wise plan, this means that the PII is true in all possible worlds. God could create indiscernibles, but the resulting creation would not be a world. To argue for this conclusion, the paper carefully examines Leibniz's mature account of metaphysical contingency. It shows that for Leibniz, only states of affairs that imply logical contradictions are metaphysically impossible. Next, it argues that the coexistence of indiscernibles would not imply a logical contradiction; it would merely imply what Leibniz calls a "moral absurdity," that is, a violation of the Principle of Sufficient Reason. This means that the PII is true contingently and - since God can do whatever is metaphysically possible-that God can create two things that are exactly alike.
\end{abstract}

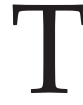
HE Principle of the Identity of Indiscernibles (PII, in short), which states that there are no two things that are exactly alike, is one of Leibniz's most influential metaphysical doctrines. It is not surprising, therefore, that Leibniz scholars have bestowed considerable attention on this principle and its place in Leibniz's system. Despite this scrutiny, central aspects of Leibniz's discussion of the PII remain controversial. The modal status of this principle is a case in

Contact: Julia Jorati <jorati.1@osu.edu> 
point. Most interpreters argue or assume that Leibniz's PII is necessary; in other words, they hold that according to Leibniz it is metaphysically impossible for indiscernible entities to coexist. ${ }^{1}$ Yet, some interpreters argue that Leibniz views the PII as contingent: indiscernible entities can coexist but God chose not to create any because they are not included in the best of all possible worlds. ${ }^{2}$ This is obviously an important debate because it concerns the grounds and the strength of one of Leibniz's most influential principles. The reasons for this controversy are not mysterious: some textual evidence and some philosophical considerations suggest that Leibniz views (or ought to view) the PII as necessary, whereas other textual evidence and other philosophical considerations suggest that it is contingent.

I will provide a new argument in favor of interpreting Leibniz's PII as contingent, in his sense of 'contingent.' More precisely, I argue that Leibniz is committed both to the truth of the PII and to the metaphysical possibility of coexisting indiscernibles. To make things more manageable, my paper focuses almost exclusively on texts from the mature period - that is, the period starting around 1695. Even though there is good evidence that the Leibniz of the middle period held the same views about the contingency of the PII, arguing for this would go beyond the scope of this paper. After all, such an argument would require an extensive analysis of the various ways in which Leibniz talks about contingency in the middle period, which at least on the surface look quite different from the ways he talks about contingency in the mature period. Hence, my main argument is based on mature texts, even though I will make suggestions about how this might apply to the middle period in a few places.

My discussion furthermore shows that the status of indiscernibles is somewhat different from the status of many other non-actual but metaphysically possible entities such as unicorns. I argue that while there are possible worlds that contain unicorns, there are no possible worlds that contain indiscernibles. ${ }^{3}$ Hence, it is my aim to show that the PII is contingent, and that it is therefore metaphysically possible for indiscernibles to coexist, even though no possible world contains indiscernibles. This may sound paradoxical, but it is not: Leibniz does not use a possible-world-semantics for modal terms and he does not hold, on my view, that all metaphysical possibilities obtain in some possible world.

1. See for instance Gonzalo Rodriguez-Pereyra's recent monograph on the PII (RodriguezPereyra 2014: 27f., 118ff.). Other interpreters who argue that the PII is necessary for Leibniz include Russell (1937: 55ff.), Rescher (1967: 48), Parkinson (1965: 134f.), Adams (1979: 12), Khamara (2006: 65), Futch (2008: 147), Jolley (2005: 86). For a tentative endorsement of an interestingly subtle interpretation of the PII as necessary, see Jauernig (2008: 224f.).

2. See, e.g., Vailati (1997: 125). It is also noteworthy that the authors of several reviews of Rodriguez-Pereyra's book express reservations about his argument that the PII is necessary. See, e.g., Della Rocca (2015), Steward (2015), Mugnai (2016).

3. I will here be building on Brown (2016). 
Before diving into the details of my interpretation, it is helpful to say a few words about God's power. This issue will come up several times in this paper because there is a direct connection between what is metaphysically possible and what God can do. In fact, the question of whether the PII is metaphysically necessary boils down to the question of whether there is a sense in which God could have created two indiscernible things. If the answer to this latter question is 'No,' the PII is metaphysically necessary; if the answer is 'Yes,' the PII is not metaphysically necessary. After all, Leibniz understands God's omnipotence as extending to everything that is metaphysically possible. ${ }^{4}$

The main argument that I am putting forward in this paper has the following structure:

1. If something does not imply a contradiction, it is metaphysically possible.

2. Violations of the PII would not imply a contradiction.

3. Thus, violations of the PII are metaphysically possible (from 1, 2).

4. God can create anything that is metaphysically possible.

5. Therefore, God can create violations of the PII (from 3, 4).

I start in Section 1 by examining Leibniz's mature account of contingency and arguing that Leibniz endorses the first premise of this argument. Next, in Section 2, I apply my interpretation of Leibnizian metaphysical necessity to the PII and show, on the basis of passages from Leibniz's late writings and systematic considerations, that the PII must be metaphysically contingent. Those are premises 2 and 3 of the argument. In Section 3, I then discuss some passages and considerations that may appear problematic for my interpretation. I also argue for premise 4 by addressing the worry that God cannot create indiscernible objects and that if premise 3 is true, premise 4 must be false. Finally, in Section 4, I argue that despite the contingency of the PII, there is no possible world that violates this principle: on the most plausible interpretation of Leibnizian compossibility, the PII is true in all possible worlds. That, in turn, can help us make sense of some passages in which Leibniz appears to describe violations of the PII as impossible.

\section{Leibnizian Metaphysical Necessity}

To determine the modal status of the PII, we first need to note that Leibniz's notion of metaphysical necessity is extremely narrow. Only propositions or states of affairs whose opposites (or negations) imply a contradiction are meta-

4. See, e.g., LC 5.76; T 171; 234.

Ergo vol. 4, no. 31 2017 
physically necessary. ${ }^{5}$ This means that Leibnizian metaphysical necessity is quite different from the way in which analytic philosophers commonly understand metaphysical necessity. To use contemporary terminology, what Leibniz calls 'metaphysical necessity' is logical necessity; it is based entirely on the logical notion of contradiction. In fact, Leibniz himself sometimes talks of logical necessity and identifies it with metaphysical necessity. In his fifth letter to Clarke, for instance, Leibniz refers to "a necessity that takes place because the opposite implies a contradiction (which necessity is called logical, metaphysical, or mathematical)" (LC 5.4; similarly in T 282). It is crucial to keep this in mind because it means that Leibnizian metaphysical necessity is much narrower than contemporary readers may be tempted to think. There are many true propositions and states of affairs whose opposites do not imply contradictions for Leibniz-or so I will argue-and that are hence contingent in Leibniz's sense. These propositions and states of affairs include ones that would count as metaphysically necessary in today's sense. For example, Leibniz would say that God's choosing the best possible world is metaphysically contingent in his sense but metaphysically necessary in today's sense. Such propositions and states of affairs are grounded, as we will see later, in Leibniz's Principle of Sufficient reason, or PSR in short.

One complication in understanding Leibniz's theory of necessity and contingency is that he provides several different accounts. Yet, his most fundamental account appears to be the one just mentioned: something is metaphysically necessary just in case the opposite implies a contradiction. Accordingly, something obtains (or is true) contingently just in case it obtains (or is true) and its opposite does not imply a contradiction. Let us call this 'the contradiction account.' On my interpretation, Leibniz's other accounts of necessity and contingency are merely ways of spelling out or making more precise the contradiction account. This is even true for the two accounts that Leibniz appears to favor in the middle period, that is, the per se possibility account and the infinite analysis account. ${ }^{6}$ Since I am focusing on the mature period here, we do not need to examine these accounts in much detail; Leibniz almost never mentions them in late texts. 7 Let me just describe very briefly how they relate to the contradiction account. First, something is per se possible just in case there is no contradiction within the thing or things under consideration. Accord-

5. See, e.g., CD 21; letter to Coste, December 19, 1707, G 3:401/AG 194; T 282.

6. For helpful in-depth discussions of these two accounts, see Adams (1994: 12ff., 25ff.).

7. This is not to suggest that Leibniz abandoned these accounts in the mature period. Even though I cannot argue for it here, my view is that Leibniz merely found other accounts of contingency more useful in the mature period-accounts that rely more directly on the distinction between what follows from the PSR and what follows from the Principle of Contradiction. 
ingly, the actual world exists contingently just in case other possible worlds are internally coherent or contradiction-free; it is irrelevant whether those worlds are consistent with external factors such as divine goodness. ${ }^{8}$ Hence, the per se account tells us where precisely contradictions need to be found in order to make something necessary-or where contradictions must not be found in order for something to be contingent. Even the infinite analysis account-also most prominent in the middle period - is arguably a way of spelling out what it means to imply a contradiction: contradictions must be revealed by a finite analysis. If no contradiction can be discovered in a finite analysis of the subject and the predicate, the statement (if true) is contingently true.

In the late years, Leibniz generally prefers different ways of spelling out his theory of necessity and contingency. ${ }^{9}$ I will argue that the PII is contingent on any of Leibniz's favored accounts in the mature period:

(a) The contradiction account: something is necessary just in case the opposite implies a contradiction. ${ }^{10}$

(b) The PSR account: something is necessary just in case it depends on the Principle of Contradiction; something is contingent just in case it depends on the PSR (and not on the Principle of Contradiction). ${ }^{11}$

(c) The moral necessity account: something is contingent just in case it is morally or physically necessary (and not metaphysically necessary). ${ }^{12}$

(d) The inclination account: something is contingent just in case it is determined by inclinations or reasons; ${ }^{13}$ reasons incline but do not necessitate. $^{14}$

8. See, e.g., 'On Freedom and Possibility,' A 6.4.1447/AG 2of. In order to understand the per se possibility of other possible worlds, it is important to note that for Leibniz, possible worlds are possible creations, or things that God can create; God is not included in possible worlds.

9. Yet, see $\operatorname{COE} 14$, a mature text in which Leibniz appears to combine the infinite analysis account with what I below call the 'PSR account,' according to which what depends on the PSR is contingent; similarly in $\mathrm{M}_{3} 6$.

10. See, e.g., CD 21; letter to Coste, December 19, 1707, G 3:401/AG 194; T 282.

11. For an endorsement of this view from the early 1680 , see 'On Freedom and Possibility,' A 6.4.1445/AG 19. For endorsements from the mature period, see, e.g., LC 5.9; COE 14.

12. See, e.g., $\mathrm{T} 237,282,367$.

13. Sometimes Leibniz appears to understand 'reasons' in such a way that this account applies only to rational actions, but it seems that he is also happy to call non-rational creaturely actions contingent because they, too, arise from inclinations or appetitions that do not necessitate. See, e.g., NE 178: "Geometrical and metaphysical 'followings' necessitate, but physical and moral ones incline without necessitating." Moral "followings" are presumably things that follow from reasons that are recognized by a rational mind, while physical "followings" are things that follow from non-rational inclinations and perceptions.

14. See, e.g., NE 199; letter to de Volder, July 6, 1701, LDV 213; letter to Jaquelot, September 4, 1704, G 6:559/WF 188; LC 5.8. 
(e) The hypothetical necessity account: something is contingent just in case it is merely hypothetically necessary (and not absolutely necessary). ${ }^{15}$

On my interpretation, we can understand all of these accounts as versions of the same view; they all get at the same distinction in different ways, providing different levels of detail about the grounds of contingency. The five accounts all build on the basic claim that something is necessary (i.e., metaphysically or absolutely necessary) just in case the opposite implies a contradiction, and something is contingent just in case it is true (or is the case) and its opposite does not imply a contradiction. This is important for my argument because it will allow me to argue that the PII is contingent on any of these accounts of contingency.

Let me explain, briefly, how these accounts come down to the same thing. That the PSR account is simply another way of spelling out the contradiction account is easy to see: that something is necessary just in case it depends on the Principle of Contradiction means that it is necessary just in case the opposite implies a contradiction. Moreover, Leibniz famously holds that all other truths or states of affairs depend on the PSR. Hence, the PSR account is simply a way of supplementing the contradiction account by spelling out the ground of contingency. The contradiction account merely says that contingent truths or states of affairs cannot be grounded in the Principle of Contradiction; the PSR account tells us in what they are grounded instead.

The moral necessity account provides us with yet another level of detail about the ground of contingency. By 'moral necessity,' Leibniz means, roughly, the determination of a wise mind by good or persuasive reasons. ${ }^{16}$ Conveniently for us, he connects this account to the contradiction account and the PSR account himself in a few texts. For instance, as he writes in his fifth letter to Clarke,

moral necessity is . . . agreeable to the great principle or ground of existences, which is that of the need for a sufficient reason, whereas absolute and metaphysical necessity depends on the other great principle of our reasonings, namely, that of essences, that is, the principle of identity or contradiction. For what is absolutely necessary is the only possible way, and its contrary implies a contradiction. (LC 5.10)

Similarly, in the Theodicy Leibniz accuses Spinoza of confusing "what is necessary by moral necessity, that is, according to the Principle of Wisdom and Goodness, with what is so by metaphysical and brute necessity, which occurs when

15. See, e.g., $\mathrm{RH}_{3} ; \mathrm{T} 53$.

16. See, e.g., $\mathrm{LC}_{5.4}$; $\mathrm{RH}_{3}$; FR 2. 
the opposite implies a contradiction" (T 174; similarly in T 282, 349, 367; CD 21). In both passages, Leibniz contrasts moral necessity with metaphysical necessity, which in turn he ties to the Principle of Contradiction. In contrast, he associates moral necessity with the Principle of Wisdom and Goodness and with the PSR. ${ }^{17}$ That makes sense since moral necessity is the determination of a wise mind by good reasons.

This already shows that the inclination account is merely a different way of making the same point as the moral necessity account: actions that are determined by reasons-or perhaps, more generally, by the inclinations of the agent-are contingent. ${ }^{18}$ Saying that reasons incline without necessitating simply means that when something is grounded in reasons or in the PSR, the opposite does not imply a contradiction. As I will explain in more detail later, failing to follow one's strongest inclination does not imply a contradiction, which means that acting in accordance with one's strongest inclination is not a metaphysical necessity.

Finally, the hypothetical necessity account is at bottom a variation of the contradiction account because Leibniz defines absolute necessity - which he contrasts with hypothetical necessity - as that whose opposite implies a contradiction. ${ }^{19}$ Conversely, something is hypothetically necessary just in case its opposite implies a contradiction only when we introduce an additional hypothesis. ${ }^{20}$ For example, even though it is not absolutely necessary that you read this sentence, it is necessary that you read it on the hypothesis that you read this entire paper. After all, reading the entire paper but not reading part of it implies a contradiction. Interestingly, Leibniz employs hypothetical necessity in one text in order to explain the sense in which it was possible for God to create just one monad, without all the others: God could have done this "absolutely, but not hypothetically, because he decided to act always most wisely and most harmoniously" (letter to Des Bosses, April 29, 1715, LDB 339/G 2:496). Thus, on the hypothesis that God acts wisely or that God's creations are harmonious, it is not possible that there be only one monad. Yet, the existence of a lonely monad is not absolutely impossible-its existence would not imply a contradiction but is merely unworthy of a wise creator.

Leibniz even connects the hypothetical necessity account to the inclination account in a very helpful passage from the Theodicy:

17. For the purposes of this paper, we can safely bracket physical necessity and the question in what sense non-rational actions are contingent because what is important here is the contingency of God's choices.

18. See, e.g., NE 178.

19. See, e.g., LC 5.10; COE 14; letter to de Volder, April 3, 1699, LDV 73.

20. See, e.g., $\mathrm{RH}_{3} ; \mathrm{T} 53$. 
as to the connection between causes and effects, it only inclined the free agent without necessitating him. ... [T]hus it does not produce even a hypothetical necessity, except in conjunction with something from outside, namely, this very maxim, that the prevalent inclination always wins. (T 53)

The idea appears to be the following: the determination of free agents by their inclinations is only a hypothetical necessity because it is only necessary on the hypothesis that the strongest inclination succeeds. Acting against one's inclinations is not absolutely or metaphysically impossible; it is merely hypothetically impossible. ${ }^{21}$ It does not imply a contradiction unless we introduce that hypothesis. The hypothesis in question can of course be derived from the PSR: since inclinations include all of the dispositions to which the agent is subject, failing to act in accordance with the balance of those inclinations would be a violation of the PSR. ${ }^{22}$

As a matter of fact, Leibniz does us the favor of mixing all of the first four accounts $^{23}$ of necessity in his fifth letter to Clarke: he accuses Clarke of confounding

metaphysical necessity and moral necessity, essences and existences. For what is necessary is so by its essence, since the opposite implies a contradiction; but a contingent that exists owes its existence to the principle of what is best, which is a sufficient reason for the existence of things. And therefore I say that motives incline without necessitating, and that there is a certainty and infallibility, but not an absolute necessity in contingent things. (LC 5.9; see also 5.4)

Cleary, Leibniz thinks that his different accounts of necessity and contingency ultimately come down to the same thing. Something is necessary just in case its opposite implies a contradiction and something is contingent just in case it is based on the PSR.

There is of course a lot more to say about these accounts. Yet, for my purposes, it suffices to note that a state of affairs is contingent if the opposite does not imply a contradiction, or if it obtains because of the PSR or because it is more appealing to God than its negation. The five accounts differ merely in how much they say about the ways in which something could fail to imply a contra-

21. I will say more about this later.

22. Strictly speaking, God could of course intervene as well and prevent a finite substance from acting in accordance with its inclinations. Yet, God only intervenes when he has a sufficient reason to intervene. Hence, the PSR also governs divine interventions.

23. If we understand 'absolute necessity' as a reference to the distinction between absolute and hypothetical necessity, it even includes the fifth account as well. 
diction: the contradiction account does not provide any such details; the PSR account notes that PSR-dependent truths are the ones that do not imply contradictions; the moral necessity account makes this more specific by dividing PSRdependent truths into morally and physically necessary ones; the inclination account elaborates on why reasons do not necessitate metaphysically; and the hypothetical necessity account helps us understand why the contradictions that we can derive when we help ourselves to certain true hypotheses do not entail a metaphysical necessity. This understanding of Leibnizian contingency allows me to argue later that the PII is contingent: the lack of indiscernibles in the actual world is a state of affairs that obtains because of God's preference for it. The coexistence of indiscernibles would not imply a contradiction and is therefore metaphysically possible.

First, however, it will be helpful to examine the contradiction account more closely. As already seen, Leibniz holds that when a wise mind chooses on the basis of reasons, its action is contingent because the opposite does not imply a contradiction. What exactly does that mean? The per se account of contingency, prominent in the middle period, sets the bar very low: all that is required is that an alternative is possible in itself, that is, that the alternative does not imply a contradiction internally. For instance, God's choice of the actual world is contingent because other possible worlds are internally consistent.

Yet, in some mature texts, Leibniz appears to set the bar quite a bit higher: he wants to say not only that other possible worlds are free of internal contradictions but also that God's creating them does not imply a contradiction. This becomes clear in the Theodicy, where Leibniz says explicitly that

metaphysically speaking, [God] could have chosen or done what was not best; but he could not have done this morally speaking. . . . [I]t implies no contradiction that God should will-directly or permissively-a thing not implying contradiction, and in this sense it is permitted to say that God can will it. (T 234)

God is genuinely omnipotent: he can do whatever is metaphysically possible. Hence, not only are non-optimal possible worlds internally contradiction-free; there is not even a contradiction in supposing that God creates one of them. That is precisely what Leibniz tells us in the fifth letter to Clarke:

[Clarke] confounds moral necessity, which proceeds from the choice of what is best, with absolute necessity; he confounds the will of God with his power. God can produce everything that is possible or whatever does not imply a contradiction, but he wills only to produce what is the best among things possible. (LC 5.76) 
Hence, even though God is determined to create the best, this action is not necessary; ${ }^{24}$ it is possible, and does not imply a contradiction, for God to create what is not best.

Is Leibniz entitled to the claim that it is metaphysically possible for God to create something other than the best? In other words, can Leibniz consistently maintain that God's creating a non-optimal world does not imply a contradiction? It might seem that the answer is a resounding 'No.' How could it not imply a contradiction for a perfectly good being to act in a sub-optimal way? Yet, I think Leibniz has a good response to this worry. Defending Leibniz against this objection is not strictly necessary for the purposes of this paper, so I will only provide a broad outline of what I take to be his solution. ${ }^{25}$ My basic proposal is the following. For Leibniz, being perfectly good means having a perfectly good nature, or having perfectly good inclinations or dispositions. ${ }^{26}$ God is perfectly good just in case God is always most strongly inclined to do what is best. Yet, it does not imply a contradiction that someone does what is not best despite being most strongly inclined to do what is best. ${ }^{27}$ An agent's failure to follow her strongest inclination would be a violation of the PSR, rather than a violation of the Principle of Contradiction. In other words, an agent's failure to act in accordance with her perfectly good nature would not imply a contradiction. There would be no sufficient reason for such an action; it would be an unmotivated, unexplained event. Yet, that does not amount to a contradiction. After all, the agent does not have contradictory properties in this scenario. By way of analogy, suppose I lift a heavy rock and then let go of it. If the rock were to rise up instead of falling, even though the strongest force to which it is subject pulls it down, the PSR would clearly be violated. However, that series of events is not logically impossible; it would merely be random or unexplained and hence lack a sufficient reason. The same holds for agents acting against their inclinations or motives. If this is correct, Leibniz is entitled to the claim that it is metaphysically possible for God to create something sub-optimal.

On the interpretation just sketched, it is legitimate to call Leibniz's system a version of necessitarianism: he holds that everything is metaphysically necessary in today's sense. Let me explain what I mean by this. By contemporary standards, Leibniz's distinction between moral and metaphysical necessity, or between truths that depend on the PSR and those that depend on the Principle

24. Leibniz states this unequivocally in a few places, for instance in a letter to de Fontenelle: "God is determined to produce other beings not by the law of necessity, as would be true if he produced everything possible, but by the law of wisdom or the law of the best, of the best ordered, of the most perfect" (April 10, 1703, FC 228/SLT 137).

25. I provide a more detailed defense in Jorati (2017: $137 \mathrm{ff}$.).

26. See, e.g., letter to Jaquelot, September 4, 1704, G 6:559/WF 189; 'Meditation on the Common Concept of Justice,' Mollat 48/Riley 50; Reply to Lamy, G 4:592/WF 166.

27. This fits very well with what I said earlier about hypothetical necessity. 
of Contradiction, is simply the distinction between two types of metaphysical necessity. The second is roughly what we would call 'logical necessity,' and the first is roughly what we would call 'metaphysical (but non-logical) necessity.' These types of necessitation invoke different principles, but neither one qualifies as contingency in the contemporary sense. After all, Leibniz holds that the existence of a God who is perfect in all ways is metaphysically necessary and that the existence and nature of such a God determines the existence and nature of everything else. While this determination is not a logical necessitation, there is no indeterminacy in this picture. Hence, what we have is a necessary first cause that determines everything else - a textbook example of necessitarianism, if we understand 'necessity' in the contemporary sense.

One helpful way to understand this determination, as well as Leibniz's claim that it is not necessitation, is the following. Leibniz holds, as already mentioned, that God can create anything that is logically possible. Hence, with respect to divine power, everything that does not imply a contradiction is possible. Yet, God does not create everything that he can create because he is also wise. When we take God's wisdom into consideration, only a subset of logically possible things are genuine options: only options that are harmonious and well ordered satisfy a wise being. And when we take God's will into consideration, only the best of these options is left as a genuine option because God's will is attracted only to what he knows to be best. ${ }^{28}$ When Leibniz says that God could have created a less perfect world, he appears to be talking about God's power (and hence the Principle of Contradiction), while bracketing God's will (and hence the PSR). We can also express this in terms of hypothetical necessity: it is only on the hypothesis that God always does what he knows to be best that sub-optimal worlds are ruled out. This means that when we take all of God's nature and the truth of the PSR into consideration, only one option is possible in our contemporary sense of 'possible'; God is determined to choose the best.

Hence, on my interpretation, the difference between the two Leibnizian types of necessity is simply a difference in the source of necessitation. What Leibniz calls 'moral necessity' or 'contingency' is, in contemporary terms, a metaphysical necessitation of minds by reasons. ${ }^{29}$ Yet, I do not think that is a problem for Leibniz. If my interpretation is correct, he is completely fine with that. When he criticizes necessitarianism, what he is criticizing is a necessitarianism like Spinoza's that denies that goodness is a fundamental explanatory principle. For Leibniz, it is immensely important that in order to explain why things are the way they are, we need to invoke God's wisdom and goodness. In other words, some things

28. See Griffin (2013: 106), who also discusses these three senses in which something is possible for God; see also Feeney (2016: 162) and Jorati (2016: 185ff.).

29. Or, perhaps more accurately and more generally, it is a necessitation of substances by inclinations. 
must be morally necessary. The world exists because it is best, not because the laws of logic rule out all alternatives. For instance, in response to Clarke's objection that Leibniz's system is fatalistic because God's actions are predetermined by reasons, Leibniz says the following: "it is not this fatality (which is only the wisest order of providence) but a brute fatality or necessity void of all wisdom and choice, which we ought to avoid" (LC 3.8, translation altered). ${ }^{30}$ Thus, Leibniz is happy to embrace a form of necessitarianism; he sometimes makes this point by calling moral necessity a "happy necessity" (e.g., T 175; 191; 344; Ta, response $8, \mathrm{G}$ 6:386).

If, as I have argued, Leibniz holds that everything is metaphysically necessary in the contemporary sense, then the PII is of course metaphysically necessary in that sense as well. If this is what interpreters who argue for the necessity of the PII are saying, I do not disagree with them. Yet, that would not be a particularly interesting result - and I do not think that contemporary Leibniz scholars are typically doing this. The interesting question is whether violations of the PII are ruled out by the Principle of Contradiction or merely by the PSR. And, plausibly, that is also what interests most interpreters who claim that the PII is necessary. To be sure, I am not suggesting that there is anything wrong with wondering whether Leibniz's best of all possible worlds or certain features of it are metaphysically necessary according to our own understanding of metaphysical necessity. That is simply a different project from one that examines whether these entities are metaphysically necessary by Leibniz's own lights. Moreover, it is important to realize that by using our own notion of necessity, we gloss over a distinction that Leibniz finds extremely important: the distinction between what depends on the Principle of Contradiction and what depends on the PSR, or the difference between what an agent can do and what she has most reason to do.

It should have become clear in this section that Leibnizian metaphysical necessity is extremely demanding: something is metaphysically necessary just in case its opposite implies a contradiction. This notion is much narrower than the contemporary way of understanding metaphysical necessity. In particular, what depends on the PSR is not metaphysically necessary for Leibniz; PSR violations do not imply logical contradictions. Leibniz in fact makes this point in a helpfully explicit way in his essay 'On the Ultimate Origination of Things' in the late 1690s: "although [etsi] the world is not metaphysically necessary, in the

30. There are many other passages in which Leibniz stresses that the necessitarianism we need to avoid is the one that does not leave room for final causation or goodness as an explanatory principle; a necessitarianism according to which some things are necessitated by their value is entirely unobjectionable. See, e.g., $\mathrm{RH}$ 3; T 173; 371f.; the preface to the Theodicy (G 6:43f.); NE 73; 'On Freedom,' A 6.4.1653/AG 94. Several other interpreters have made a similar point; see, e.g., Griffin (2013: 59, 81), Lagerlund and Myrdal (2006: 172), Adams (1994: 20). I discuss it in more detail in Jorati (2017: 133ff.). 
sense that its contrary implies a contradiction or logical absurdity, it is, however, physically necessary or determined, in the sense that its contrary implies imperfection or moral absurdity" (G 7:304/AG 151; translation slightly altered). There is nothing logically wrong with other worlds; their existence is ruled out not on the basis of logic but on the basis of the PSR, which dictates that the best of all possible worlds is the one that gets actualized.

\section{The Contingency of the PII}

Armed with a better understanding of Leibnizian contingency, we can now turn to the PII and examine its modal status. As already mentioned, I will argue that according to Leibniz it is metaphysically possible for indiscernibles to coexist. Hence, since the PII is true, it is contingent. First, note that Leibniz sometimes claims that the PII is grounded in the PSR; he also explains the PII with reference to divine wisdom. For instance, Leibniz claims in his fifth letter to Clarke that he infers from the PSR

that there are not in nature two real, absolute beings, indiscernible from each other, because if there were, God and nature would act without reason in treating the one otherwise than the other, and that therefore God does not produce two pieces of matter perfectly equal and alike. (LC 5.21)

This is strong evidence that Leibniz derives the PII from the PSR; he says that we know that we will not find two indiscernible things in nature simply because we know that God does nothing without a reason. In the same section, Leibniz goes on to say that

[the] supposition of two indiscernibles, such as two pieces of matter perfectly alike, seems indeed to be possible in abstract terms, but it is not consistent with the order of things, nor with the divine wisdom by which nothing is admitted without reason. (LC 5.21)

On a straightforward reading, this means that the supposition of two indiscernibles does not imply a contradiction and is hence metaphysically possible-it is "possible in abstract terms." ${ }^{11}$

31. Of course, someone could object that Leibniz is merely asserting the possibility of supposing indiscernibles, not the possibility of indiscernibles (see Rodriguez-Pereyra 2014: 123, who makes this point). And in fact, Leibniz does sometimes talk about supposing something in order to then show that it cannot be the case, for instance in geometry (see LC 4.17); this is the strategy of an indirect proof. Moreover, it might be relevant that Leibniz merely calls indiscernibles possible 
Along similar lines, Leibniz states a few paragraphs later:

[w]hen I deny that there are two drops of water perfectly alike, or any two other bodies indiscernible from each other, I do not say it is absolutely impossible to suppose them, but that it is a thing contrary to the divine wisdom, and which consequently does not exist. (LC 5.25)

Likewise, just one paragraph after this, he says that the supposition of two indiscernibles is "false and contrary to the great principle of reason" (LC 5.26). Based on the discussion of metaphysical necessity from the previous section, it should be clear that these passages are strong evidence for the contingency of the PII..$^{22}$ Leibniz explicitly says that the supposition of indiscernibles is merely contrary to divine wisdom or the order of things, but not absolutely impossible. In other words, the coexistence of indiscernibles is ruled out by the PSR but not by the Principle of Contradiction. Moreover, in 'On Nature Itself,' Leibniz calls the coexistence of indiscernibles "alien to the nature and order of things" (Section 13, G 4:514/AG 164). These are strongly suggestive passages. 33

A further passage supporting the contingency of the PII is from the New Essays, where Leibniz's spokesperson states that if there were atoms with the same shape and size, "they would then be indistinguishable in themselves and discernible only by means of external denominations with no internal foundation; which is contrary to the greatest principle of reason" (NE 231). Here again, Leib-

\footnotetext{
"in abstract terms" in this passage. After all, Leibniz sometimes uses the term 'abstract' to refer to incomplete notions. See, e.g., 'Primary Truths': "perfect similarity is found only in incomplete and abstract notions, where things are considered only in a certain respect, but not in every way" (A 6.4.1645/AG 32). If this is what he means, something could be possible in abstract terms while also being metaphysically impossible. Nevertheless, I find it most plausible that when Leibniz says in LC 5.21 that the supposition of two indiscernibles is possible in abstract terms, he is saying that the proposed scenario-and not just the supposition of it, or the abstract, incomplete notion of it-is contradiction-free. This impression is confirmed by the fact that he contrasts "possible in abstract terms" with "consistent with ... divine wisdom" and hence with the PSR. Moreover, it is confirmed a few paragraphs later, in LC 5.25 and 26 (see below).

32. It is admittedly possible to read these passages in such a way that they do not imply the contingency of the PII. Rodriguez-Pereyra provides such a reading, for instance (2014: 123ff.). Rodriguez-Pereyra thinks that in these passages Leibniz is trying to make it sound as if he were committed to the contingency of the PII without actually saying so (2014: 125). For instance, he thinks that Leibniz purposely says that supposing indiscernibles "seems" possible, which does not imply that it is possible. (See also Footnotes 31 and 58.) Likewise, Rodriguez-Pereyra points out that stating that indiscernibles are ruled out by the PSR does not mean that they are metaphysically possible - they could in addition be ruled out by the Principle of Contradiction (2014: 123). This interpretation might make sense if we are considering only the Clarke correspondence. Yet, when we look beyond it, we see that there is evidence for the contingency of the PII in other texts, as I am about to show; there are also strong systematic reasons for the contingency of Leibniz's PII, as we will soon see.
}

33. See also LC 4.3 and a letter to Johann Bernoulli, January 1699, GM 3:565/AG 17of. 
niz suggests that scenarios in which the PII is violated are contrary to the PSR, or the "greatest principle of reason." If he thought that they were also contrary to the Principle of Contradiction, it would be strange to put it in these terms. A noteworthy feature of this passage is that it explicitly ties the PII to Leibniz's Principle of Individuation, or the doctrine that it must be possible to individuate things through their intrinsic properties. In fact, the passage uses the Principle of Individuation in order to argue for the PII. We can reconstruct this argument as follows:

1. If something violates the PII, it also violates the Principle of Individuation.

2. Violations of the Principle of Individuation are ruled out by the PSR.

3. Therefore, violations of the PII are ruled out by the PSR.

This argument is interesting both because it ties the PII to the Principle of Individuation - on which I will rely below-and because it argues for the PII from the PSR. 34

It is important to note that there are at least two ways in which the PSR rules out the coexistence of indiscernibles. One, which Leibniz appears to discuss in some of the passages just mentioned, is that God would not have a reason to create indiscernibles or to treat them differently; he would be acting without a sufficient reason. For instance, if God were to create two indiscernible things, what reason could he possibly have to place one here and one there, rather than the other way around? These types of PSR-based arguments against indiscernibles occur, for instance, in the Clarke Correspondence (e.g., LC 5.21). A second way in which the PSR rules out indiscernibles has to do with individuation: there would not be a sufficient reason for the non-identity of two indiscernible things; their non-identity would be a brute, unexplainable fact. After all, Leibniz holds that only a difference in intrinsic properties could be a sufficient reason for nonidentity. This way of ruling out indiscernibles is also found in some of the passages quoted earlier, for instance in NE 231.

Even apart from the textual evidence for the contingency of the PII, I find it immensely plausible for systematic reasons that Leibniz's PII must be metaphysically contingent. After all, it is difficult to see how the coexistence of two indiscernible things could imply a logical contradiction. Contradictions arise when we predicate two incompatible properties of one thing or when we predicate a property of a thing whose concept is logically incompatible with that property. For example, it would be a contradiction for a world to both contain Gottfried and not contain Gottfried, or for Gottfried to both be and not be born in Leipzig. Likewise, it would be a contradiction for Gottfried to be a god, because Gott-

34. A similar argument appears to be contained in LC 5.26. 
fried's concept is logically incompatible with being a god. But how could there be a contradiction if in addition to Gottfried, there existed another human being indiscernible from Gottfried?

Here, Leibniz's doctrine of compossibility becomes relevant, that is, his claim that only some collections of possibles are compossible; others are incompossible. This doctrine is supposed to help explain why God does not actualize all possibles; moreover, it is supposed to explain how possibles are grouped into possible worlds. Interpreters disagree about the correct interpretation of Leibniz's doctrine of compossibility, but on the interpretation that I find most plausible, the coexistence of two finite substance never implies a logical contradiction. Incompossibility, on this view, does not arise from the Principle of Contradiction but rather from the PSR. 35 But even if this interpretation is not correct, it is unclear how the coexistence of two indiscernibles things would give rise to a logical contradiction. There are some interpreters who hold that the coexistence of some substances would imply logical contradictions; these interpreters are proponents of what are sometimes called 'logical interpretations.' 36 Yet, these interpreters appear to hold that those contradictions arise from contradictory predicates, or from perceptions of different and incompatible worlds. For instance, on such interpretations a monad that perceives a world containing Gottfried cannot coexist with a monad that perceives a world not containing Gottfried, because those perceptions are logically incompatible. Even if that is correct, it does not explain how a contradiction could arise from two qualitatively identical substances. Those substances would, in virtue of being indiscernible, not have any incompatible properties: while 'Fa \& Fa' implies a contradiction, 'Fa \& Fb' does not. More generally, if there are no contradictions within a substance - that is, no contradictory properties - it is unclear how adding another, qualitatively identical substance could give rise to a contradiction. In other words, it is unclear why it should not be possible for an internally consistent creaturely essence or complete concept to be actualized twice.

But could God really have created two Gottfrieds? If we take seriously Leibniz's claim that God can create whatever is metaphysically possible-even things that are incompatible with God's wisdom and goodness, and even things that violate the PSR - then the answer is 'yes'. It is metaphysically possible, on this interpretation, for God to actualize Gottfried's complete concept twice, resulting in two substances with all the same intrinsic properties. Granted, this may appear to go against what Leibniz sometimes says about complete concepts - in some texts, Leibniz insists or presupposes that there can be only one substance

35. I argue for this interpretation in Jorati (2016).

36. See Messina and Rutherford (2009) for a helpful discussion; for someone who endorses the logical interpretation, see Mates (1986: $75 \mathrm{f}$.). 
per concept. 37 Yet, that is arguably because in those texts Leibniz is taking the PSR (or his Principle of Individuation) for granted. In other words, he is not concerned with metaphysical necessity, but with something less demanding. I will provide more evidence for this interpretive move later.

Let us take a look at what complete concepts are and why it must be possible to instantiate them multiple times. As I understand Leibniz, complete concepts are basically blueprints for substances: they are divine ideas, each of which contains an exhaustive description of a substance that God could create. If that is the correct way to view complete concepts, there is no logical reason why there could not be more than one instantiation of any given complete concept. After all, they are merely qualitative descriptions of a possible substance; there is nothing included in complete concepts that is not in principle shareable. Leibniz rejects the existence of primitive haecceities, or non-qualitative properties. ${ }^{38}$ Hence, there is nothing in Gottfried's complete concept that logically prevents God from instantiating it twice, resulting in two indiscernible Gottfrieds.

Of course, there would be no sufficient reason for the non-identity of these indiscernibles - their non-identity would be an unexplained or brute fact. Because they are qualitatively identical and lack any additional non-qualitative properties, nobody-not even God-could tell the two Gottfrieds apart. God would not even be able to think about one without thinking about the other because God's ideas about a substance plausibly just are the complete concepts. 39 That would be an extremely weird and confusing state of affairs, definitely unworthy of a wise creator. Yet, I contend, it would not imply a contradiction and is hence metaphysically possible. After all, it is plausible that Leibniz's Principle of Individuation itself derives from the PSR and is hence contingent. Leibniz adopts his Principle of Individuation because there must be a sufficient reason for the

37. See, e.g., 'Discourse on Metaphysics' Section 9 (A 6.4.1541/AG 41f.), where Leibniz appears to say that the PII follows from his doctrine of complete concepts. This is one reason why I focus on the mature period: a full explanation of whether this connection to complete concepts entails the necessity of the PII would be quite complicated. To say just a few words about this, I do not think it has this implication because the doctrine of complete concepts already depends on the PSR-driven assumption that "all true predication has some basis in the nature of things" ('Discourse on Metaphysics' Section 8, A 6.4.1540/AG 41). (I thank an anonymous referee for asking me to elaborate on this.)

38. See, e.g., Adams (1979: 9), who brings this out nicely; similarly in Adams (2002: 854).

39. If this is indeed the only way in which God can think about substances, God would not even have a way to double-check whether he has created one or two instantiations of a concept. He would merely know that he created two because he knows that he willed to create two. That is admittedly strange, and might be one (among many) reasons why God would never create two indiscernibles. Yet, the doctrine that God can only think about substances by thinking about complete concepts may have similarly strange consequences even without indiscernibles: how would God double-check whether he has successfully actualized a concept? As in the case of indiscernibles, God's knowledge of what he has created might have to depend simply on his knowledge of what he has willed to create. (I thank an anonymous referee for asking me to elaborate on this.) 
distinctness of individuals and, he insists, this sufficient reason must lie in their intrinsic properties. Otherwise, the non-identity of those individuals would be a brute fact, which is ruled out by the PSR. Yet, brute facts are not ruled out by the Principle of Contradiction. There is nothing contradictory about brute facts. As a result, the coexistence of two Gottfrieds does not amount to a contradiction; it merely violates the PSR because it implies that there is a brute fact.

The Clarke correspondence contains textual evidence for the contingency of the Principle of Individuation: Leibniz states that "if two things perfectly indiscernible from each other did exist, they would be two, but that supposition is false and contrary to the great principle of reason" (LC 5.26). On the most straightforward interpretation of this statement, it implies that brute individuation is ruled out only by the PSR and is hence metaphysically possible. After all, Leibniz appears to be describing the existence of two brutely individuated things as coherent and conceivable - they would indeed be two distinct thingseven though we know that such a scenario does not obtain in the actual world because it is ruled out by the PSR. In a similar vein, Leibniz's spokesperson says in a New Essays passage from which I already quoted earlier that

if there were atoms, ... it is obvious that since they could have the same size and shape they would then be indistinguishable in themselves and discernible only by means of external denominations with no internal foundation; which is contrary to the greatest principle of reason. (NE 23of.)

Here again, Leibniz describes the brute individuation of things - or more precisely, an individuation without internal foundation - as something that we can coherently describe but that is ultimately ruled out by the PSR.

It is true that once we presuppose that it must be possible for God to individuate the substances that he creates, or that he must be able to think about each one as an individual, indiscernibles are ruled out. And in some contexts, it of course makes sense for Leibniz to presuppose these things. When he is exploring the nature of the actual world, it is legitimate to take the Principle of Individuation-as well as the PSR more generally-for granted, and reject any supposition that would violate these principles. Yet, such a rejection does not imply metaphysical impossibility. It is important to note that, somewhat paradoxically, some metaphysical doctrines are metaphysically contingent for Leibniz. In fact, he openly acknowledges that the PSR grounds many metaphysical truths. He boasts in a letter to Clarke that the PSR and the PII "change the state of metaphysics. That science becomes real [reelle $]^{40}$ and demonstrative by means of these

40. Interestingly, Leibniz also refers to "real metaphysics" in his 'Conversation of Philarete and Ariste' and ties it to fitness, i.e., the Principle of the Best: "to justify the laws of dynamics, we 
principles, whereas before it did generally consist in empty words" (LC 4.5$).^{41}$ Clearly, many metaphysical doctrines in Leibniz's system rely on the PSR. They are doctrines about what the ultimate structure of our world must be, given that it was created by a wise God who does nothing without a sufficient reason and who prizes intelligibility and harmony. Hence, some metaphysical doctrines are metaphysically contingent-which makes sense when we remember that Leibnizian metaphysical necessity is what we today would label logical necessity. The PII, on my interpretation, is one such doctrine.

\section{Some Objections and Replies}

So far, we have seen strong reasons for interpreting Leibniz's PII as contingent. Yet, there are also some textual and systematic considerations that may seem to count against the contingency of this principle. In this section, I will examine what I take to be the most significant ones and argue that they are not ultimately strong enough to outweigh the evidence for the PII's contingency from the previous section.

First of all, violations of the PII are in an important sense unintelligible. Even God would not fully understand a scenario in which the PII is violated. As a result, one might worry that violations of the PII are not metaphysically possible, since unintelligibility arguably implies metaphysical impossibility. To put this worry in a slightly different way: God can create only what he can understand. In fact, Leibniz sometimes claims that the divine intellect is the ground of possibilities. ${ }^{2}$ Only what God understands is metaphysically possible. Hence, someone might object that if God cannot understand violations of the PII, they are not metaphysically possible. 43

Yet, this objection is not ultimately persuasive. For Leibniz, there appear to

must have recourse to the real metaphysics [Metaphysique reelle] and to the principles of fitness which affect souls" (G 6:588/AG 264). It also seems relevant that in LC 4.4, in the paragraph immediately before the passage about the PSR's and the PII's role in real metaphysics, Leibniz tells Clarke that atoms and the vacuum were "confuted . . . by the principles of true [veritable] metaphysics." Real metaphysics, for Leibniz, appears to be a PSR-driven metaphysics. For a helpful discussion of what Leibnizian "real metaphysics" is, see Lodge (2010).

41. Leibniz repeats this point, in different words, in LC 5.26; there, he contrasts his own metaphysics, which contains demonstrations and rules out things "which superior reasons do not admit" with the type of metaphysics that is "handled like a science of mere words."

42. See, e.g., M 46; CD 7f.; T 184, 189.

43. Considerations like this might make it tempting to introduce something like Kant's distinction between real and merely logical possibility, and to say that the coexistence of indiscernibles is merely logically possible but not really possible. Yet, Leibniz's writings do not support such a distinction, to the best of my knowledge. The closest thing that they do support, as already seen, is a distinction between what is possible with respect to God's power and what is possible with respect to God's wisdom and his goodness. 
be two different types of unintelligibility: PSR-dependent unintelligibility and Principle-of-Contradiction-dependent unintelligibility. Only the latter type is a sign of metaphysical impossibility. To see this distinction, imagine an unmotivated choice such as God's choice of the second-best world. This choice would be unintelligible merely in the PSR-dependent way: there is no sufficient reason for the choice and hence the choice is not fully intelligible. We cannot fully understand why this choice would occur. The same would be true of a genuinely random quantum event or the rock mentioned earlier, which rises up instead of falling. Yet, this type of unintelligibility is different from a Principleof-Contradiction-dependent unintelligibility, such as the unintelligibility of a square circle or of a human being who is simultaneously sitting and standing. These latter scenarios are unintelligible because they involve contradictions, not merely because they would violate the PSR.

PII violations, I contend, are unintelligible merely in the PSR-dependent way: there is no sufficient reason for distinguishing the indiscernibles from one another; their distinctness is a brute fact. It is in this sense that God cannot fully understand a scenario in which there are two indiscernibles. For reasons seen earlier, however, PII violations are intelligible in the Principle-of-Contradictiondependent way: we can describe those violations without logical contradictions, just as we can describe unmotivated choices or other brute facts without logical contradictions. To put this slightly differently, there is a clear sense in which God knows perfectly well what he would have to do in order to create two indiscernibles, and what the resulting creation would be like. It is possible to provide a complete description of such a creation. God could think to himself something like this: “There is a substance $a$ with properties F, G, H, etc. (or: with complete concept $\mathrm{C}$ ), and there is a substance $b$ with exactly the same properties (or the same concept $C$ ), and $a \neq b$." This description does not contain any logical contradictions ${ }^{44}$ and it is a complete description of the scenario. Hence, in this sense,

44. One might object that it is a contradiction if, as suggested before, God cannot think about substances except through their complete concept. Hence, one might worry, God cannot consistently think " $a \neq b$ " if $a$ and $b$ have the same complete concept, because he cannot think of one without thinking of the other. (I thank an anonymous referee for pushing this objection). Yet, I do not think this objection ultimately succeeds. There is a difference between God's thinking about particular, actual substances and his thinking abstractly about metaphysically possible states of affairs. In order to think abstractly about states of affairs, God merely needs to think logically consistent descriptions of those states of affairs. Such abstract descriptions can simply stipulate that two distinct things have the same concept, or that two things with the same properties are not identical. This would happen in precisely the same way in which we can abstractly think of two instantiations of an incomplete concept, such as two separate squares whose sides are 1 inch long. There is nothing incoherent about that abstract thought. God's thinking about particular, actual substances is different. God cannot simply stipulate that one and the same idea first refers to one actual substance and then to another, because he can only make that stipulation if he can already think of them separately. 
the coexistence of indiscernibles is perfectly intelligible. There is of course something problematic about the described scenario, which would lead a wise being to reject it immediately as a candidate for actualization: the non-identity of $a$ and $b$ is an unexplained or brute fact. Still, as already seen, that does not mean that there is anything metaphysically impossible about the scenario. And, as we will see later, it is plausibly metaphysical possibility or Principle-of-Contradictiondependent intelligibility that determines what God can do.

In fact, the PSR-dependent unintelligibility of PII violations is arguably the reason why Leibniz sometimes calls them "absurd." 45 The fact that Leibniz uses this terminology should not be treated as strong evidence that the PII is metaphysically necessary, pace interpreters like Rodriguez-Pereyra. ${ }^{6}{ }^{6}$ Indeed, Leibniz uses the term 'absurd' in several other texts to describe what appear to be metaphysically possible states of affairs that violate the PSR. As already seen, he says in 'On the Ultimate Origination of Things' that a non-optimal world implies not a logical contradiction or "logical absurdity" but that it rather "implies imperfection or moral absurdity" (G 7:304/AG 151). Hence, he explicitly acknowledges a type of absurdity that occurs when the PSR is violated. In fact, the distinction between logical and moral absurdity from this passage corresponds neatly to my distinction between 'Principle-of-Contradiction-dependent unintelligibility' and 'PSR-dependent unintelligibility.' Similarly, Leibniz writes to Coste in 1707 that it is "false and absurd" to imagine that it is possible for God or a human being to choose without reasons, or against all of their reasons, "because one of the greatest principles of good sense is that nothing ever happens without a cause or determining reason" (December 19, 1707, G 3:402/AG 194). 47 Here again, Leibniz uses the term 'absurd' to describe something that is metaphysically possible but ruled out by the PSR. Hence, the fact that Leibniz sometimes calls violations of the PII 'absurd' is not compelling evidence for their metaphysical impossibility.

In addition to the passages that describe PII violations as absurd, there are a few other texts that may appear to support the necessity of the PII. $4^{8}$ Yet, a closer look at these texts reveals that they are not at all conclusive; they need not be read in that way. In fact, no passage that I have seen says explicitly that

45. See, e.g., 'Primary Truths,' A 6.4.1647/AG 33; letter to Casati, 1689, A 2.2.289. Both of these texts are from the middle period.

46. Rodriguez-Pererya claims that calling violations of the PII 'absurd' "strongly suggests that [Leibniz] thought the principle to be necessary" (2014: 91; similarly 2014: 128, 158).

47. See also 'Preliminary Specimen,' where Leibniz says that perpetual motion would require a greater power in the effect than in the cause, which is "absurd for sure" (GM 6:287/AG 106). For other passages in which Leibniz uses 'absurd' or 'absurdity' for what seem like PSR violations, see 'Specimen of Dynamics,' GM 6:245/AG 129; letter to de Fontenelle, April 10, 1703, FC 227/SLT 137; letter to Jaquelot, October 6, 1706, Grua 66/SLT 207.

48. Rodriguez-Pereyra provides a helpful list of passages in which Leibniz mentions the PII, and many of them contain modal language; see Rodriguez-Pereyra (2014: 15ff.). 
indiscernibles are metaphysically impossible or that the PII is metaphysically or absolutely necessary. Some of them do use modal language; they state, for instance, that indiscernibles cannot exist, that it is impossible for two things to be perfectly alike, or that there must be differences between individual things. Yet, modal terms like these do not always denote metaphysical necessity for Leibniz. The terms could simply mean that indiscernibles are ruled out by God's wisdom or by the PSR, that is, that co-existing indiscernibles are morally absurd or physically, hypothetically, or morally impossible. It is possible-and in fact likely, given the evidence I have already marshaled for the contingency of the PII-that in these passages Leibniz is engaging in metaphysical, PSR-based reasoning, arguing that certain things must be true about the actual world. 49

Let us take a look at some of these texts, starting with two particularly interesting examples from the middle period ${ }^{50}$ before moving on to mature texts. In a piece probably composed between 1683 and 1685 , Leibniz says that "[t]here cannot be two singular things [singularia] that are similar in all respects, for example two eggs. For it is necessary that something can be said about the one which cannot be said about the other" ('Notationes Generales,' A 6.4.554). Here, Leibniz employs two modal terms to describe the force of the PII: 'cannot' and 'necessary.' ${ }^{51}$ Yet, this text is a helpful reminder that we should not read too much into such terms, because the passage continues as follows: "Otherwise they could be substituted for one another, and there would be no reason why they could not therefore be said to be one and the same." This continuation suggests that indiscernibles are impossible only on the hypothesis that there is a reason for the non-identity of any two distinct things. Hence, this passage does not provide strong reasons for interpreting the PII as metaphysically necessary.

Similarly, Leibniz writes in 'Primary Truths' - a text composed around 1689 - that "in nature, 52 there cannot be two individual things that differ in number alone. For it certainly must be possible to explain why they are different, and that explanation must derive from some difference they contain" (A 6.4.1645/AG

49. As I mentioned toward the end of Section 2, Leibniz holds that real metaphysics is only possible because we can assume the truth of the PSR. Thus, it makes sense that he presupposes the PSR when he engages in metaphysical reasoning-even when he does not explicitly say so.

50. My positive case for the contingency of the PII is based on mature texts, but it still seems worthwhile to discuss some textual objections from the middle period. Ultimately, it would not be a problem if the middle period texts contradict my interpretation. I am inclined to think that Leibniz viewed the PII as contingent even in the middle period, but it is not my goal in this paper to argue for this. If Leibniz considered the PII to be necessary in the middle period-or at least sometimes toyed with the idea that it is necessary -it would not affect my case for the contingency of the PII in Leibniz's mature system.

51. Leibniz uses similar language in other middle period texts, for instance in remarks on a letter from Arnauld (A 2.2.48) and in a letter to Arnauld, July 14, 1686 (A 2.2.58).

52. Here, as in some other places, Leibniz appears to contrast 'in nature' with 'in the abstract.' See Footnote 31. 
32, emphasis omitted). This passage may seem like evidence for the necessity of the PII because of the modal language it employs. Yet, it is noteworthy that the justification this passage provides for the PII is that there must be an explanation or reason for the non-identity of distinct things. In other words, the justification is Leibniz's Principle of Individuation, and ultimately the PSR. A look at the passage's context reinforces this impression. The first sentence begins: "From these considerations it also follows that," clearly referring back to the previous paragraph, which introduces the PSR. Hence, this passage actually describes the PII as following from the PSR. Even though it is not clear what theory of contingency Leibniz endorses in 'Primary Truths,' the mature Leibniz holds that what follows from the PSR is contingent-a view that we can also find articulated in several texts from the middle period. 53

Let us now turn to mature texts that may appear to be evidence for the necessity of the PII. One interesting passage comes from the New Essays, in which Leibniz's spokesperson says that he can demonstrate "that each [substantial thing] must always differ from every other in respect of intrinsic denominations" (NE 110). ${ }^{54}$ This text not only uses modal terminology; it also states that this claim about the PII can be demonstrated. Yet, that does not mean that the PII is metaphysically necessary because as already seen, Leibniz thinks we can use the PSR to demonstrate metaphysical truths. ${ }^{55}$ That kind of demonstration is entirely compatible with the contingency of those truths.

Next, let us consider two passages from a letter to De Volder from June 20, 1703. In that letter, Leibniz first states that "[t]hings that differ must [debent] differ in some way, i.e., have a specifiable difference in them. . . . [I]t cannot happen [fieri nequit] in nature that there are two bodies that are perfectly equal and similar at the same time" (LDV 259). Later in the same letter he adds that "[i]t is necessary [necesse est] that entelechies differ-i.e., that they not be completely like one another" (LDV 263). These passages are reminiscent of what Leibniz says in the 'Monadology':

53. 'Primary Truths' is a notoriously complicated text because in it, Leibniz appears to derive the PSR from his principle that the predicate must be contained in the subject in any true proposition (A 6.4.1645/AG 31). This can be taken to imply that Leibniz views the PSR, and whatever follows from it, as necessary in this text. I am not sure that this is the case, since it is unclear whether the principle about truth must be viewed as necessary. Yet, if it is the case, 'Primary Truths' is an anomaly, even within the middle period, and should not be regarded as reliable evidence about Leibniz's considered views on the modal status of the PII. (I thank an anonymous referee for raising this objection.)

54. The New Essays also contains passages that make the PII sound contingent; we have already seen one such passage earlier (NE 23of.), which argues for the PII from the PSR.

55. See, e.g., LC 4.5. 
It is also necessary [Il faut $]^{56}$ that each monad be different from each other. For there are never two beings in nature that are perfectly alike, two beings in which it is not possible to discover an internal difference, that is, one founded on an intrinsic denomination. ( $\mathrm{M}$ 9)

From what we have already seen, it should be obvious why none of these passages is strong evidence for the metaphysical necessity of the PII: the modal language in these texts can easily be read as referring to a hypothetical necessity, or to a physical or moral necessity. Given that God does everything for a reason, or given that the PSR is true, there must be ways to individuate all actual substances from each other. 57

The most challenging passages are from the Clarke correspondence, which is surprising since-as seen earlier-this correspondence is also the source of strong evidence for the contingency of the PII. In his fourth letter to Clarke, Leibniz writes:

To suppose two things indiscernible is to suppose the same thing under two names. And therefore to suppose that the universe could have had at first another position of time and place than that which it actually had, ... such a supposition, I say, is an impossible fiction. (LC 4.6)

Two aspects of this passage are noteworthy: it claims that supposing two indiscernibles is supposing "the same thing under two names" and it states that the supposition is "an impossible fiction." Both of those aspects may seem like strong evidence for the metaphysical necessity of the PII. Moreover, it may seem that the responses that I have given to other passages do not work here. To make matters even worse, Leibniz writes later in the same letter:

To say that God can cause the whole universe to move forward in a right line ... without making otherwise any alteration in it, is another chimerical supposition. For two states indiscernible from each other are the same state, and consequently, it is a change without any change. (LC 4.13)

56. The fact that Leibniz uses 'il faut' here, instead of the more technical term 'il est necessaire,' might already give us reason to doubt that he is talking about metaphysical necessity. Leibniz uses 'il faut' quite loosely, for instance when warning us about mistakes we "must" not make (e.g., $\mathrm{M}_{46}$ and $\mathrm{M} 71$ ).

57. It is also worth nothing the context of the De Volder passages: in LDV 259, Leibniz explains that people are prone to introducing "monstrosities that are contrary to the true philosophy," such as co-existing indiscernibles, because these people "do not attend to reasons" and instead use only "incomplete and abstract ... notions, which thought supports but which nature does not recognize." While this is not conclusive evidence, the claim that people who suppose indiscernibles do not sufficiently "attend to reasons" does shed some doubt on the reading according to which indiscernibles are ruled out by the principle of contradiction. 
This passage echoes the two noteworthy aspects of the previous passage: Leibniz calls the supposition of indiscernibles "chimerical" and says that indiscernible states would be "the same state."

I admit that these passages from the fourth letter to Clarke are problematic for my interpretation. As is so often the case in Leibniz scholarship, we will to some extent have to weigh the evidence on both sides. And in my view, when we weigh the passages just considered against the evidence for the PII's contingency that I laid out in the previous section, the latter is clearly stronger. Yet, there are a few other things to say about the fourth letter to Clarke. First of all, it is worth noting that Leibniz's last word on the issue is the fifth letter to Clarke, not the fourth. And in the fifth letter, Leibniz explicitly states, as already seen, that "if two things perfectly indiscernible from each other did exist, they would be two, but that supposition is false and contrary to the great principle of reason" (LC 5.26). In other words, Leibniz appears to be taking back his claims from the fourth letter that the indiscernibles would be one thing, or rather, he appears to be clarifying that he did not mean that they would genuinely be one thing. He merely meant that the scenario would be contrary to the PSR and can hence be ruled out. This is evidence that we should not take the claims from the fourth letter at face value. Leibniz may be overstating his case in the fourth letter for rhetorical reasons; his point might simply be that because there would be no way to individuate two indiscernible things, the principle of individuation says that they would not in fact count as two different things. ${ }^{8}$

Second, it not true that calling something 'chimerical' or a 'fiction' always means that it is metaphysically impossible in Leibniz's sense.59 We do not even

58. Some interpreters suggest that in the fifth letter, Leibniz is granting merely for the sake of argument that indiscernibles are logically possible in order to show that they would nevertheless not exist since the PSR excludes them also (e.g., Jolley 2005: 86; Broad 1946: 154). Along slightly different lines, Rodriguez-Pereyra argues that Leibniz does not think he can convince Clarke of the necessity of the PII and therefore settles, in the fifth letter, for convincing him of the truth of the PII, pretending that he never meant to describe it as necessary (2014: 124f.). Those are indeed possible readings, and I admit that the dialectical situation of the Clarke correspondence is complicated. Yet, my reading, on which Leibniz is genuinely clarifying his own position in the fifth letter, does not obviously seem less plausible. And after weighing all of the evidence for and against the necessity of the PII, my reading strikes me as more plausible.

59. It is true that Leibniz sometimes uses those terms to describe what may appear to be metaphysical impossibilities. The strongest such passage that I know is LC 4.2: "A simple will without any motive is a fiction, not only contrary to God's perfection, but also chimerical and contradictory, inconsistent with the definition of the will." This passage associates 'chimerical' and 'fiction' with 'contradictory' and hence with metaphysical impossibility. See also a 1698 text in which Leibniz says it is a "chimerism" to perform impossible combinations of ideas, such as when someone holds that physical substances are pure extension even though it is not possible for a substance to be nothing but extension ( $G_{3: 225}$ ). This latter passage is not conclusive because Leibniz may need the PSR in order to show that substances cannot consist in mere extension; the combination of ideas may be impossible in the sense that it is ruled out by the PSR. Yet, even aside from that, there are other passages in which Leibniz clearly uses the term 'chimera' and 'fiction' for things 
need to go beyond the Clarke correspondence to find passages in which Leibniz uses these terms for what appear to be mere PSR violations. For instance, toward the end of the fifth letter, Leibniz writes:

It is true that [the PSR] has been neglected out of carelessness on many occasions, but that neglect has been the true cause of chimeras, such as are (for instance) an absolute real time or space, a vacuum, atoms, attraction in the scholastic sense, a physical influence of the soul over the body ... and a thousand other fictions. (LC 5.127; similarly in LC 5.58) ${ }^{60}$

It is hence clear that Leibniz sometimes uses the terms 'chimera' and 'fiction' for things that are merely absurd in the PSR-dependent sense: their existence is ruled out by the PSR. Hence, using those terms for violations of the PII is not conclusive evidence for the PII's metaphysical necessity.

\section{Possible Worlds, Compossibility, and the PII}

I will now argue that, according to a plausible interpretation of Leibnizian possible worlds and of compossibility, there are no possible worlds that contain indiscernibles, even though indiscernibles are metaphysically possible. On the interpretation I have in mind, it is not the case that any combination of possibles constitutes a possible world; not even any combination that is logically compatible. ${ }^{61}$ To qualify as a world, a collection of possibles must harmonize, or be connected in a particular way. Among other things, this means that were these possibles actualized, their perceptions would jointly give rise to a law-governed,

that violate the PSR but not the Principle of Contradiction, as I am about to show. Hence, the term need not be read as implying metaphysical impossibility.

6o. See also a 1698 letter, in which Leibniz responds to Bayle's objections to his essay 'New System': "when I said that the soul would still feel all that it feels now even if there were only it and God in the world, I was only employing a fiction" (G 4:517/PT 202); later in the same text, he calls a passion without a corresponding action a "metaphysical fiction" comparable to a vacuum, and says that both are "against the order of things" (G 4:519/PT 204). These are additional cases in which Leibniz describes something that is metaphysically possible as a 'fiction' because it would violate the PSR. For additional passages in which he uses 'chimerical' or 'chimera' in ways that do not imply metaphysical impossibility, see, e.g., NE 196: if we allow that it is possible to go against all reasons, "we are having recourse to such chimeras as the Scholastics" bare faculties and occult qualities, in which there is neither rhyme or reason." See also NE $265 \mathrm{f} .:$ "it is best to say that possible ideas become merely chimerical when the idea of actual existence is groundlessly attached to them - as is done by those who think they can find the Philosopher's Stone."

61. I will not argue for this interpretation here because others have already done so convincingly. See, e.g., Messina and Rutherford (2009), Brown (2016: 211f.), Feeney (2016: 163.). 
intelligible phenomenal world. ${ }^{62}$ Perfections (or active states) in one thing must correspond to imperfections (or passive states) in another. Or, to approach the issue from a different angle, a possible world must satisfy God's wisdom; it must be unified by a wise, overarching plan or law. Collections of possibles that do not satisfy God's wisdom are not possible worlds; they are not compossible. God has the power to actualize such collections, but if he had done so, he would not have created a world.

Why are there no possible worlds that contain indiscernibles, even though indiscernibles are metaphysically possible? ${ }^{63}$ In other words, why would the coexistence of indiscernible things fail to satisfy divine wisdom? There are multiple ways to arrive at this conclusion. Most straightforwardly, a collection containing indiscernibles would violate the Principle of Individuation; the indiscernibles would have to be individuated brutely, as we saw earlier. Hence, that collection would violate the PSR, as already seen, and it would not be fully intelligible in the PSR-dependent sense. Those are obvious reasons why such a collection would not be satisfactory to divine wisdom.

On the phenomenal level, a collection that contains indiscernibles would furthermore violate Leibniz's principle that there must be an exact correspondence between actions and passions, and that passions must be explainable, at the level of phenomena, through corresponding actions. This is a principle that any harmonious collection of creatures must obey. To see why indiscernibles would violate this principle, suppose that God were to create two indiscernible dogs. Because their perceptions would be qualitatively identical, those two dogs would perceive their surroundings from the same perspective. That would mean that there would be two dogs in the same place at the same time. ${ }^{64}$ In order to be part of a spatio-temporal order, the dogs would need to interact (ideally, or phenomenally) with other things. For instance, suppose that the collection also contains a human being that perceives getting bitten by a dog with those spatiotemporal properties. The passive state of the human being would correspond to an action in two dogs, each of which is singly sufficient for phenomenally ex-

62. Gregory Brown (2016) argues persuasively that this phenomenal world also needs to be a mechanistic world without a vacuum.

63. My interpretation of the status of indiscernibles is structurally similar to Gregory Brown's interpretation of the status of a spatial vacuum (Brown 2016): indiscernibles and spatial vacua are metaphysically possible even though they are not included in any possible world. This similarity is no coincidence; there are important connections between Leibniz's arguments against the vacuum and against indiscernibles.

64. Supposing that God merely creates two indiscernible dog souls would not help. After all, to exhibit the kind of order and connectedness that is characteristic of worlds, each soul must arguably have a body that it unifies and animates. A soul that does not animate a body, or two souls animating one body, would be violations of the connectedness and order that is required for worlds. 
plaining the corresponding passion. That, however, violates Leibniz's principles about the correspondence between actions and passions. This problem has an analogue at the metaphysical level of description: a collection containing two indiscernible individuals would fail to be unified by a wise plan or law because one of the two indiscernibles is entirely expendable; it does not add anything of value because any role that it could play in the plan is already played flawlessly by the other. There is no sufficient reason for duplicating substances and thus a wise plan would not include such a duplication.

What we have learned in this section gives us another way of explaining why some passages make the PII sound necessary: when Leibniz talks about possibilities, he is sometimes particularly interested in the possibilities that God considered when deciding which possible world to actualize. That is, he is sometimes interested in possible worlds. And in that context, indiscernibles are already off the table; they are not included in any of the collections of possibles that appeal to divine wisdom.

\section{Conclusion}

On my interpretation, Leibniz's PII is contingent, in Leibniz's sense of 'contingent': violations of the PII would not imply contradictions and are hence metaphysically possible. Moreover, I contend that God could have created multiple indiscernibles, even though it is true that if he had done so, the resulting creation would not be fully intelligible even to God. Yet, if God had actualized multiple indiscernibles, he would not have created a world; he would instead have created a collection of substances that lack the order and connectedness that is required for worldhood. As a result, the coexistence of indiscernibles is metaphysically possible even though there is no possible world in which there are indiscernibles. This is a status that indiscernibles arguably share with a vacuum and other metaphysically possible entities that Leibniz holds to be incompatible with divine wisdom.

\section{Acknowledgments}

This paper has benefited immensely from conversations with Dominik Perler, Martha Bolton, Sebastian Bender, Martin Lin, Michael Della Rocca, and the participants of the 2016 Leibniz Society of North America Conference in Houston, TX. I also thank two anonymous Ergo referees for their detailed and insightful comments. 


\section{Abbreviations of Leibniz Texts and Editions}

Note: If an English edition is explicitly cited (or associated with an abbreviation), translations are taken from that English edition, unless otherwise specified. In all other cases, translations are mine. Quotations include all italics from the original text, unless otherwise specified.

A Sämtliche Schriften und Briefe (1923-2015). Deutsche Akademie der Wissenschaften (Ed.). Akademie Verlag. Cited by series, volume, page.

AG Philosophical Essays (1989). Roger Ariew and Daniel Garber (Eds. and Trans.). Hackett.

CD Causa Dei, appended to the Theodicy (1710). Cited by section number as in G 6:439-462.

COE Observations on the Book Concerning the Origin of Evil, appended to the Theodicy (1710). Cited by section number as in G 6:400-436.

FC Lettres et opuscules inédits de Leibniz (1854). Louis Alexandre Foucher de Careil (Ed.). Durand.

FR Preliminary Dissertation on ... Faith and Reason, published with the Theodicy (1710). Cited by section number as in G 6:49-101.

G Die philosophischen Schriften von Gottfried Wilhelm Leibniz (Vols. 1-7) (1875-1890). Carl Immanuel Gerhardt (Ed.). Weidmann. Reprinted Georg Olms, 1978. Cited by volume and page.

GM Leibnizens mathematische Schriften (Vols. 1-7) (1849-1863). Carl Immanuel Gerhardt (Ed.). Asher. Reprinted Georg Olms, 1971. Cited by volume and page.

Grua Textes inédits d'après des manuscripts de la Bilbliothèque provinciale d'Hanovre (Vols. 1-2) (1948). Gaston Grua (Ed.). Presses Universitaires de France.

LC The Leibniz-Clarke-Correspondence (1715-1716). G 7:352-440; cited by number of letter and number of paragraph (e.g., LC 5.2: Letter 5, Paragraph 2); translation from Correspondence (2000). Roger Ariew (Ed. and Trans.). Hackett.

LDB The Leibniz-Des Bosses Correspondence (2007). Brandon Look and Donald Rutherford (Eds. and Trans.). Yale University Press.

LDV The Leibniz-De Volder Correspondence (2013). Paul Lodge (Ed. and Trans.). Yale University Press.

M Monadology (1714). Cited by section as in G 6:607-623; translation from AG 213-225.

Mollat Mittheilungen aus Leibnizens ungedruckten Schriften (1893). Georg Mollat (Ed.). Haessel.

NE New Essays on Human Understanding (1704). Cited by page numbers from A.6.6; translation from New Essays on Human Understanding (1996). Peter Remnant and Jonathan Bennett (Eds. and Trans.). Cambridge University Press.

PT Philosophical Texts (1998). Roger Woolhouse and Richard Francks (Eds. and Trans.). Oxford University Press.

RH Reflections on Hobbes, appended to the Theodicy (1710). Cited by section number as in G 6:388-399.

Riley Political Writings (1972). Patrick Riley (Ed. and Trans.). Cambridge University Press. 
SLT The Shorter Leibniz Texts: A Collection of New Translations (2006). Lloyd Strickland (Ed. and Trans.). Continuum.

$\mathrm{T}$ Theodicy (1710). Cited by section number as in G 6:102-365; translations mine.

Ta Summary of the Controversy Reduced to Formal Arguments, appended to the Theodicy (1710). G 6:376-387.

WF Leibniz's 'New System' and Associated Texts (1997). Roger Woolhouse and Richard Francks (Eds. and Trans.). Oxford University Press.

\section{Bibliography}

Adams, Robert Merrihew (1979). Primitive Thisness and Primitive Identity. The Journal of Philosophy, 76(1), 5-26. https://doi.org/10.2307/2025812

Adams, Robert Merrihew (1994). Leibniz: Determinist, Theist, Idealist. Oxford University Press.

Adams, Robert Merrihew (2002). Review of Substance and Individuation in Leibniz, by J. A. Cover and John O'Leary-Hawthorne. Mind, 111(444), 851-855. https://doi. org/10.1093/mind/111.444.851

Broad, C. D. (1946). Leibniz's Last Controversy with the Newtonians. Theoria, 12(3), 143168. https://doi.org/10.1111/j.1755-2567.1946.tb00506.x

Brown, Gregory (2016). Leibniz on the Possibility of a Spatial Vacuum and the Connectedness Condition on Possible Worlds. In Gregory Brown and Yual Chiek (Eds.), Leibniz on Compossibility and Possible Worlds (201-226). Springer. https://doi. org/10.1007/978-3-319-42695-2_9

Della Rocca, Michael (2015). Review of Rodriguez-Pereyra, Leibniz's Principle of the Identity of Indiscernibles. Notre Dame Philosophical Reviews, 06(33).

Feeney, Thomas (2016). Leibniz, Acosmism, and Incompossibility. In Gregory Brown and Yual Chiek (Eds.), Leibniz on Compossibility and Possible Worlds (145-174). Springer. https://doi.org/10.1007/978-3-319-42695-2_7

Futch, Michael J. (2008). Leibniz's Metaphysics of Time and Space. Springer. https://doi. org/10.1007/978-1-4020-8237-5

Griffin, Michael V. (2013). Leibniz, God, and Necessity. Cambridge University Press.

Jauernig, Anja (2008). The Modal Strength of Leibniz's Principle of the Identity of Indiscernibles. In Daniel Garber and Steven Nadler (Eds.), Oxford Studies in Early Modern Philosophy (Vol. 4, 191-225). Oxford University Press.

Jolley, Nicholas (2005). Leibniz. Routledge.

Jorati, Julia (2016). Divine Faculties and the Puzzle of Incompossibility. In Gregory Brown and Yual Chiek (Eds.), Leibniz on Compossibility and Possible Worlds (175-199). Springer. https://doi.org/10.1007/978-3-319-42695-2_8

Jorati, Julia (2017). Leibniz on Causation and Agency. Cambridge University Press. https:// doi.org/10.1017/9781108131629

Khamara, Edward J. (2006). Space, Time, and Theology in the Leibniz-Newton Controversy. Ontos. https://doi.org/10.1515/9783110328301

Lagerlund, Henrik and Peter Myrdal (2006). Possible Worlds and the Nature of Choice in Leibniz. Studia Leibnitiana, 38(2), 156-176.

Lodge, Paul (2010). The Empirical Grounds of Leibniz's "Real Metaphysics." Leibniz Review, 20, 13-36. https://doi.org/10.5840/leibniz2010202 
Mates, Benson (1986). The Philosophy of Leibniz: Metaphysics and Language. Oxford University Press.

Messina, James and Donald Rutherford (2009). Leibniz on Compossibility. Philosophy Compass, 4(6), 1-16. https://doi.org/10.1111/j.1747-9991.2009.00262.x

Mugnai, Massimo (2016). Review of Rodriguez-Pereyra, Leibniz's Principle of the Identity of Indiscernibles. British Journal for the History of Philosophy, 24(2), 378-380. https://doi. org/10.1080/09608788.2015.1116976

Parkinson, George Henry Radcliffe (1965). Logic and Reality in Leibniz's Metaphysics. Oxford University Press.

Rescher, Nicholas (1967). The Philosophy of Leibniz. Prentice Hall.

Rodriguez-Pereyra, Gonzalo (2014). Leibniz's Principle of the Identity of Indiscernibles. Oxford University Press. https://doi.org/10.1093/acprof:oso/9780198712664.001.0001

Russell, Bertrand (1937). A Critical Exposition of the Philosophy of Leibniz (2nd ed.). George Allen \& Unwin.

Steward, Stephen (2015). Review of Rodriguez-Pereyra, Leibniz's Principle of the Identity of Indiscernibles. Leibniz Review, 25, 105-119. https://doi.org/10.5840/leibniz2015257

Vailati, Ezio (1997). Leibniz and Clarke: A Study of their Correspondence. Oxford University Press. 
